\title{
Article \\ The Effect of Different Types of Internal Curing Liquid on the Properties of Alkali-Activated Slag (AAS) Mortar
}

\author{
Guang-Zhu Zhang ${ }^{1}$, Xiao-Yong Wang ${ }^{2,3, *(\mathbb{C})}$, Tae-Wan Kim ${ }^{3}$, Jong-Yeon Lim ${ }^{3}$ and Yi Han ${ }^{3}(\mathbb{C}$ \\ 1 Catholic College, Songsim Global Campus, The Catholic University of Korea, Bucheon-si 14662, Korea; \\ zhangks@catholic.ac.kr \\ 2 Department of Architectural Engineering, Kangwon National University, Chuncheon-si 24341, Korea \\ 3 Department of Integrated Energy and Infra System, Kangwon National University, \\ Chuncheon-si 24341, Korea; tkim@kangwon.ac.kr (T.-W.K.); jongyeon.lim@kangwon.ac.kr (J.-Y.L.); \\ hanyii@kangwon.ac.kr (Y.H.) \\ * Correspondence: wxbrave@kangwon.ac.kr; Tel.: +82-33-250-6229
}

Citation: Zhang, G.-Z.; Wang, X.-Y.; Kim, T.-W.; Lim, J.-Y.; Han, Y. The Effect of Different Types of Internal Curing Liquid on the Properties of Alkali-Activated Slag (AAS) Mortar. Sustainability 2021, 13, 2407.

https://doi.org/10.3390/su13042407

Academic Editors: Enzo Martinelli and Seungjun Roh

Received: 25 January 2021

Accepted: 19 February 2021

Published: 23 February 2021

Publisher's Note: MDPI stays neutral with regard to jurisdictional claims in published maps and institutional affiliations.

Copyright: (c) 2021 by the authors. Licensee MDPI, Basel, Switzerland. This article is an open access article distributed under the terms and conditions of the Creative Commons Attribution (CC BY) license (https:// creativecommons.org/licenses/by/ $4.0 /)$.

\begin{abstract}
This study shows the effect of different types of internal curing liquid on the properties of alkali-activated slag (AAS) mortar. $\mathrm{NaOH}$ solution and deionized water were used as the liquid internal curing agents and zeolite sand was the internal curing agent that replaced the standard sand at $15 \%$ and $30 \%$, respectively. Experiments on the mechanical properties, hydration kinetics, autogenous shrinkage (AS), internal temperature, internal relative humidity, surface electrical resistivity, ultrasonic pulse velocity (UPV), and setting time were performed. The conclusions are as follows: (1) the setting times of AAS mortars with internal curing by water were longer than those of internal curing by $\mathrm{NaOH}$ solution. (2) $\mathrm{NaOH}$ solution more effectively reduces the AS of AAS mortars than water when used as an internal curing liquid. (3) The cumulative heat of the AAS mortar when using water for internal curing is substantially reduced compared to the control group. (4) For the AAS mortars with $\mathrm{NaOH}$ solution as an internal curing liquid, compared with the control specimen, the compressive strength results are increased. However, a decrease in compressive strength values occurs when water is used as an internal curing liquid in the AAS mortar. (5) The UPV decreases as the content of zeolite sand that replaces the standard sand increases. (6) When internal curing is carried out with water as the internal curing liquid, the surface resistivity values of the AAS mortar are higher than when the alkali solution is used as the internal curing liquid. To sum up, both $\mathrm{NaOH}$ and deionized water are effective as internal curing liquids, but the $\mathrm{NaOH}$ solution shows a better performance in terms of reducing shrinkage and improving mechanical properties than deionized water.
\end{abstract}

Keywords: internal curing liquid; $\mathrm{NaOH}$ solution; deionized water; alkali-activated slag; autogenous shrinkage; strength

\section{Introduction}

Alkali-activated slag (AAS) requires less energy than ordinary Portland cement (OPC) in the manufacturing process $[1,2]$ and has gained widespread interest in the construction manufacturing sector. In particular, the use of alkali-activated slag can effectively reduce carbon emissions [3]. The materials required to make AAS concrete usually include slag, aggregate (fine or coarse aggregates), and various alkali activators [4]. Nevertheless, AAS mortar is limited in practical engineering applications because of the large amount of autogenous shrinkage [5]. Some related studies reported that the influencing factors affecting the autogenous shrinkage of AAS concrete mainly include the slag fineness [6,7], the type and amount of alkali activators [8], and the curing conditions [9].

It is well known that internal curing is proven to reduce autogenous shrinkage in concrete $[10,11]$. The autogenous shrinkage of concrete is most closely related to cement hydration [12]. The porous material is treated as a reservoir, and the water absorbed by the 
reservoir is released with the hydration reaction, thus ensuring a high relative humidity around the reservoir and thus reducing the occurrence of autogenous shrinkage [13]. Mo et al. [14] reported the combined action of biochar with a porous material and $\mathrm{MgO}$ expansion admixtures in cement paste. It is reported that the biochar provided a relatively high internal relative humidity to the cement paste and enhanced the ability of $\mathrm{MgO}$ to compensate for shrinkage. Liu et al. [15] found, by etching cenospheres, that the thin glass crystal films on the surfaces of the cenospheres were removed, and water absorption reached $180 \mathrm{wt} \%$. When the internal relative humidity was below $95 \%$, the internal curing water was released by cenospheres and, eventually, the autogenous shrinkage was almost completely eliminated. Liu et al. [16] found that coral sand with a maximum particle size of $0.6 \mathrm{~mm}$ is an ideal material for ultra-high-performance concrete to reduce autogenous shrinkage, and using no more than $20 \%$ (vol\%) is recommended to obtain the highest strength. There are some similarities between the autogenous shrinkage of AAS concrete and OPC concrete, so an increasing number of studies on internal curing to reduce the autogenous shrinkage of AAS concrete are being conducted.

However, porous materials as internal curing agents to control the autogenous shrinkage of AAS mortars are still in the preliminary stages. Currently, the most commonly used internal curing materials to reduce the autogenous shrinkage of AAS mortars are superabsorbent polymers (SAPs) [17,18]. Li et al. [17] found that SAPs were released from the internal curing liquid before $8 \mathrm{~h}$, which ultimately could significantly reduce the autogenous shrinkage of the AAS mortar (about 58\%). Oh et al. [18] used three different activators $\left(\mathrm{Na}_{2} \mathrm{SiO}_{3}, \mathrm{NaOH}\right.$, and $\mathrm{Na}_{2} \mathrm{CO}_{3}$ solutions, alone or in combination) to observe the effect of SAPs on the autogenous shrinkage of AAS mortars. However, there are two obvious disadvantages to SAPs. Firstly, the involvement of SAPs limits the development of the compressive strength of AAS mortars. In addition, a SAP can only be used in a dry state because it swells after absorbing water [19], so the internal curing liquid can only change with the type of activator [18]. Although the autogenous shrinkage was significantly reduced in each group of specimens due to the presence of SAPs, no clear explanation was given to explain the mechanism of autogenous shrinkage of AAS mortars by the absorption of different internal curing liquids by SAPs. Especially when considering the similarity between the autogenous shrinkage of OPC concrete and AAS mortar systems [20], the mechanism of the effect of water as an internal curing liquid on the autogenous shrinkage of AAS mortars is worth investigating.

Some researchers are concerned about the abovementioned drawbacks, and therefore have started to choose lightweight aggregates (LWAs) as internal curing agents for AAS studies. However, few studies have reported on the use of LWAs to reduce AAS mortar. It was reported by Bentz and Sakulich [21] that LWA is an adequate internal curing agent, and LWAs can easily mitigate the autogenous shrinkage of AAS mortar. Darshan et al. [22] used expanded shale as an internal curing agent that can significantly reduce the autogenous shrinkage of AAS mortar. Considering that an excessive amount of LWAs replacing normal silica sand has no significant effect on reducing autogenous shrinkage and may also adversely affect the strength and ductility of the mortar, the optimal amount to use is $20 \%$ [22]. In addition, other researchers have confirmed that recycled aggregates can reduce the autogenous shrinkage of AAS mortars. Lee et al. [23] found that a larger particle size of the recycled aggregate means that the specific surface area is smaller and the efficiency of the internal curing liquid being released into the matrix is limited. In addition, recycled aggregates have the potential to react, leading to blocked transport channels and resulting in reduced internal curing effectiveness. Therefore, although recycled aggregates can reduce autogenous shrinkage, this ability is limited. Existing research has confirmed that LWAs are also effective as internal curing agents to reduce autogenous shrinkage for AAS mortars. LWAs cannot impose limitations on strength development; however, since research into the internal curing efficiency of LWAs is not satisfactory, it is necessary to find a new, more efficient LWA to slow down the autogenous shrinkage of AAS mortars. 
Based on the literature about internal curing, we can find the weak points of previous studies: (1) The effect of water as an internal curing liquid on the autogenous shrinkage of OPC concrete systems has been intensely studied. However, study of the effect on AAS mortars is very limited. (2) Currently available LWAs are capable of reducing autogenous shrinkage without causing significant loss of compressive strength, but the efficiency of reducing autogenous shrinkage is not satisfactory. (3) SAPs cannot be pretreated independently as the internal curing liquid changes with the activator type because the swelling after water absorption is significant, resulting in a fixed order of raw material placement during the processing of concrete. Therefore, it is essential to find a new porous material that can be pretreated to change the internal curing liquid and significantly reduce autogenous shrinkage.

Existing AAS literature has used internal curing liquids, which is the same as alkali activators. The effects of different types of internal curing liquid are not considered in existing AAS literature. To fill this gap, this study performed a series of experimental studies to clarify the effects of different types of internal curing liquids on the properties of alkali-activated slag (AAS) mortar. Zeolite sand was used as the internal curing agent to replace parts of the standard sand. Before mixing, zeolite was presoaked with internal curing liquid. During the hardening process, the internal curing liquid is released, and the autogenous shrinkage of alkali-activated slag is lowered. The new findings of this study are as follows: (1) Zeolite sand is an ideal material for internal curing because of its internal pores, which can absorb internal curing liquid and effectively reduce autogenous shrinkage. (2) Water as an internal curing liquid can significantly reduce the compressive strength, although it is effective at reducing autogenous shrinkage. (3) The mechanisms by which water and $\mathrm{NaOH}$ solution reduce autogenous shrinkage of AAS mortar are different. Water can reduce autogenous shrinkage, but there is a dilution effect caused by the negative effect of compressive strength and hydration kinetics. On the contrary, the $\mathrm{NaOH}$ solution does not have this adverse effect.

This study's main aim is to produce sustainable alkali-activated slag concrete with lower autogenous shrinkage, lower hydration heat, and higher compressive strength. Additionally, because the internal curing method can effectively reduce autogenous shrinkage, the contents of shrinkage reducing admixtures and expansive admixtures can be lowered. Summarily, the internal curing technique is useful for the sustainable construction of infrastructures.

\section{Materials and Methods}

\subsection{Materials and Sample Preparation}

The fineness of granulated ground blast furnace slag (GGBFS) is $405 \mathrm{~m}^{2} / \mathrm{kg}$. In addition, the density of GGBFS is $2.68 \mathrm{~kg} / \mathrm{m}^{3}$. Table 1 shows the chemical constituents of GGBFS. In this study, the activator for accelerating the GGBFS reaction was $\mathrm{NaOH}$ tablets, which were of analytical grade and supported by Daejung. The $\mathrm{NaOH}$ tablets had a purity of $97 \%$ and were dissolved in deionized water and then cooled to room temperature for one day before being used for mixing to produce AAS mortars.

In this study, two types of internal curing liquids ( $\mathrm{NaOH}$ liquid and deionized water) were used. The zeolite sand has minimum and maximum particle sizes of 1 and $3 \mathrm{~mm}$, respectively. Table 2 shows the physical and chemical characteristics of zeolite sand. The teabag method was used to measure the amount of internal curing liquid absorbed by zeolite sand [24]. The internal curing liquid absorption ratio is defined as the ratio of the increased mass after absorption to the zeolite sand mass in the dry state. Figure 1 shows the teabag method results. Zeolite sand does not increase in the $\mathrm{NaOH}$ solution absorbed at around $4 \mathrm{~h}$ and reaches saturation at around $6 \mathrm{~h}$ when absorbing water. The final absorptions of $\mathrm{NaOH}$ liquid and water are 5.76 and $8.08 \mathrm{wt} \%$, respectively. The ability of porous materials to absorb water is much more efficient than in alkaline solutions. Similar results were reported in the study of Li et al. [17]. 
Table 1. Chemical constituents of granulated ground blast furnace slag (GGBFS).

\begin{tabular}{cc}
\hline Oxides (wt.\%) & GGBFS \\
\hline $\mathrm{SiO}_{2}$ & 31.73 \\
$\mathrm{CaO}$ & 38.76 \\
$\mathrm{Al}_{2} \mathrm{O}_{3}$ & 15.81 \\
$\mathrm{MgO} \mathrm{Fe}_{2}$ & 7.46 \\
$\mathrm{SO}_{3}$ & 0.56 \\
$\mathrm{~K}_{2} \mathrm{O}$ & 2.68 \\
$\mathrm{TiO}_{2}$ & 0.65 \\
$\mathrm{MnO}$ & 0.44 \\
$\mathrm{Loss}$ & 0.17 \\
\hline
\end{tabular}

Table 2. Physical and chemical characteristics of zeolite sand.

\begin{tabular}{cc}
\hline & Zeolite Sand \\
\hline Physical properties & \\
Density $\left(\mathrm{g} / \mathrm{cm}^{3}\right)$ & 2.2 \\
Specific surface area $\left(\mathrm{m}^{2} / \mathrm{g}\right)$ & 460 \\
Minimum particle size $(\mathrm{mm})$ & 1 \\
Maximum particle size $(\mathrm{mm})$ & 3 \\
Chemical analysis $(\%)$ & 65.23 \\
$\mathrm{SiO}_{2}$ & 1.98 \\
$\mathrm{CaO}$ & 13.43 \\
$\mathrm{Al}_{2} \mathrm{O}_{3}$ & 1.33 \\
$\mathrm{MgO}$ & 1.63 \\
$\mathrm{Fe}_{2} \mathrm{O}_{3}$ & - \\
$\mathrm{SO}_{3}$ & - \\
$\mathrm{K}_{2} \mathrm{O}$ & - \\
$\mathrm{TiO}_{2}$ & - \\
$\mathrm{MnO}^{2}$ & 16.31 \\
$\mathrm{Loss}$ & \\
\hline
\end{tabular}

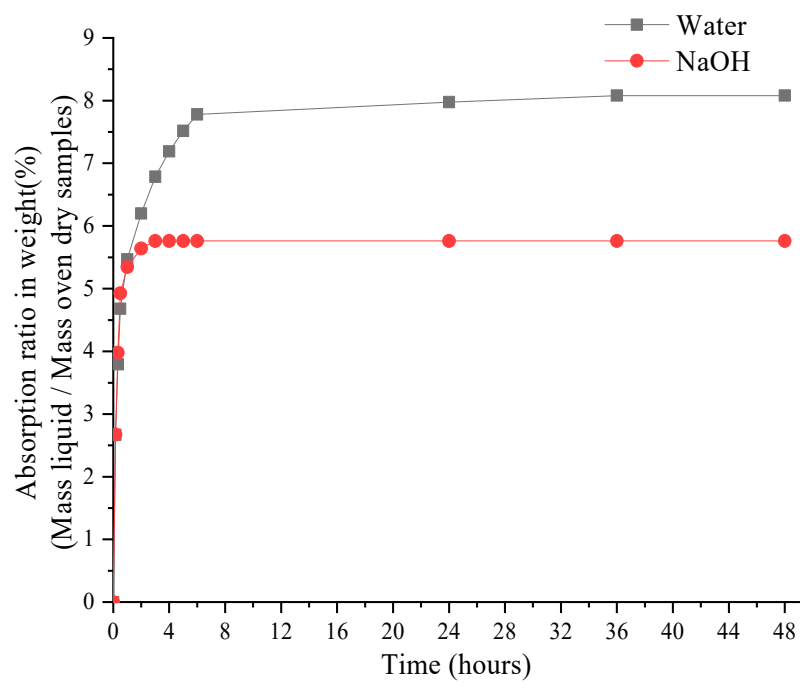

Figure 1. Time vs. $\mathrm{NaOH}$ solution and water absorption of zeolite sand.

The mix proportions of all AAS mortars are shown in Table 3. The proportions of slag, standard sand, and liquid were in the ratio of 1,2 , and 0.55 , respectively, for all AAS mortars. Labels starting with $\mathrm{W}$ and A represent AAS mortars cured by water and $\mathrm{NaOH}$ liquids, respectively. The labels with a $\mathrm{Z}$ and number represent the zeolite mass fractions of standard sand. According to the above rules for editing the specimen numbering, the 
control group without internal curing was defined as Z0. For the Z0 mixture, the binder is slag. Moreover, the $\mathrm{NaOH}$ solution was used as the activator for $\mathrm{Z} 0$. Using water as the internal curing liquid, standard mortars with $15 \%$ and $30 \%$ zeolite sand replacements were defined as $\mathrm{W}-\mathrm{Z} 15$ and $\mathrm{W}-\mathrm{Z} 30$, respectively. Using $\mathrm{NaOH}$ solution as the internal curing liquid, standard mortars with $15 \%$ and $30 \%$ zeolite sand replacement were defined as A-Z15 and A-Z30, respectively. The liquid-to-binder ratio $(\mathrm{l} / \mathrm{b})$ of AAS mortar without internal curing $(\mathrm{Z0})$ is 0.55 . For the specimens containing zeolite sands, the basic $1 / \mathrm{b}$ (corresponding to the liquid not absorbed by the zeolite) of AAS with internal curing was the same as $\mathrm{Z0}$. The liquid (absorbed by zeolite sand)-to-binder ratio is marked as $1 / \mathrm{b}_{\mathrm{IC}}$. The total $1 / \mathrm{b}$ of AAS mortars with internal curing was the sum of the basic $1 / \mathrm{b}$ and $1 / \mathrm{b}_{\mathrm{IC}}$. The $\mathrm{NaOH}$ liquid and water absorption of zeolite sand are 5.76 and $8.08 \mathrm{wt} \%$ of dry zeolite mass. Therefore, the $1 / \mathrm{b}$ of W-Z15, W-Z30, A-Z15, and A-Z30 was 0.574, 0.598, 0.567, and 0.585 , respectively. Slag, standard sand, and presoaking zeolite sand using a mortar mixer were stirred at a low speed for $30 \mathrm{~s}$. NaOH liquid was added to all powders and stirred at a low speed for $2 \mathrm{~min}$. Then we stopped for $30 \mathrm{~s}$ and scraped off the underagitated powder from the mortar mixer's inner wall. The mixing continued at high speed for another $2 \mathrm{~min}$.

Table 3. Mix proportions.

\begin{tabular}{|c|c|c|c|c|c|c|c|c|}
\hline \multirow[b]{2}{*}{$\begin{array}{l}\text { Mixture } \\
\text { Name }\end{array}$} & \multirow[b]{2}{*}{ Activator } & \multirow{2}{*}{$\begin{array}{c}\text { Internal } \\
\text { Curing Liquid }\end{array}$} & \multirow[b]{2}{*}{ Slag } & \multicolumn{3}{|c|}{ Liquid/Binder } & \multicolumn{2}{|c|}{ Sand/Binder } \\
\hline & & & & $\begin{array}{c}\text { Basic Liq- } \\
\text { uid/Binder }\end{array}$ & $\begin{array}{c}\text { Additional } \\
\text { Liquid/Binder }\end{array}$ & $\begin{array}{c}\text { Total Liq- } \\
\text { uid/Binder }\end{array}$ & $\begin{array}{c}\text { Sand } \\
/ \%\end{array}$ & $\begin{array}{l}\text { Zeolite } \\
\text { Sand } / \%\end{array}$ \\
\hline Z0 & \multirow{5}{*}{$\begin{array}{l}\mathrm{NaOH} \\
\text { Solution }\end{array}$} & - & \multirow{5}{*}{1} & \multirow{5}{*}{0.55} & - & 0.55 & 100 & - \\
\hline A-Z15 & & $\mathrm{NaOH}$ & & & 0.017 & 0.567 & 85 & 15 \\
\hline A-Z30 & & Solution & & & 0.035 & 0.585 & 70 & 30 \\
\hline W-Z15 & & Deionized & & & 0.024 & 0.574 & 85 & 15 \\
\hline W-Z30 & & Water & & & 0.048 & 0.598 & 70 & 30 \\
\hline
\end{tabular}

\subsection{Test Methods}

\subsubsection{Setting Time}

Vicat needle inspection, which was according to ASTM C191 [25], calculated the setting time of AAS mortars. All AAS mortar specimens were at $20 \pm 1^{\circ} \mathrm{C}$. During the examination, a protective film protected the mortar from water evaporation from the mortar.

\subsubsection{Autogenous Shrinkage}

The autogenous shrinkage test was carried out according to ASTM C1698 [26]. Because internal relative humidity and internal temperature serve as important factors affecting autogenous shrinkage [27], this analysis simultaneously assessed autogenous shrinkage, internal relative humidity, and internal temperature of AAS mortars. We changed the ASTM C1698 (West Conshohocken, PA, USA) measurement system by installing a sensor in the middle of the corrugated plastic tube to monitor the internal relative humidity and internal temperature. A polyvinyl chloride tube covered the sensor. Information about the changed unit can be found in a previous study [28]. AAS mortars were primed at $20 \pm 1{ }^{\circ} \mathrm{C}$ and cured at $20 \pm 1^{\circ} \mathrm{C}$.

\subsubsection{Compressive Strength Test}

This research aimed to ascertain the effects of different internal curing liquids on the early-age compressive strength of AAS mortars. Therefore, the target ages are three and seven days. A compressive strength test was carried out according to ASTM C39 [29]. The specimen size required for the compressive strength test was a $50 \mathrm{~cm}$ cube. Fresh mortars were thrown into the mold for curing for $24 \mathrm{~h}$. After $24 \mathrm{~h}$ of curing, we cut the mold and sealed the mortars before they reached the target age. Each experimental group examined three specimens, and the compressive strength test used the average of the three sets of test data collected. 


\subsubsection{Isothermal Calorimetry}

TAM-Air (New Castle, DE, USA) was used to calculate the hydration heat. Equipment was supplied by TA Instruments (New Castle, DE, USA). Mortar samples were tested at an ambient temperature of $20^{\circ} \mathrm{C}$ for $72 \mathrm{~h}$. The paste has usually been manipulated as a research target in previous studies. The purpose of this study is to investigate the effect of different internal curing liquids on the heat of hydration of AAS mortars. Therefore, mortars were the main object of this study in this experiment, in which zeolite sand was used as an internal curing agent to replace parts of the standard sand. For each experiment group, $10 \mathrm{~g}$ of mortar was weighed and placed in the isothermal calorimetry channel for measurement.

\subsubsection{Ultrasonic Pulse Velocity (UPV) Test}

The ultrasonic pulse velocity test device was supplied by Proceq Pundit Lab. The experimental operation was performed in accordance with ASTM C 597-16 [30]. The main advantages of the device included its lightness, nondestructive nature, and automatic detection. The principle of operation of the device is that a P-wave with a pulse of $45 \mathrm{kHz}$ is transmitted by the transmitter of the device through the sample and to the receiver according to the target period. The test results give a qualitative indication of the strength and homogeneity of the mortar. The target ages of the test were three and seven days. Each group of specimens was tested three times, and the average of the three results was taken for discussion.

\subsubsection{Surface Electrical Resistivity (SER)}

The surface electrical resistivity determination was carried out according to AASHTO $\mathrm{T}$ 358. The specimen under investigation was cylindrical, with a diameter of $102 \mathrm{~mm}$ and a height of $204 \mathrm{~mm}$. The instrument used for this test was a four-point Wenner surface test system supplied by Screening Eagle (Switzerland). The target ages for the tests were three and seven days. Each group of specimens was subjected to three experiments, and the average of three measurements was taken as the data for discussion.

\section{Results and Discussion}

\subsection{Setting Time}

Figure 2 shows the initial and final setting times of all AAS mortars. Firstly, the setting times of AAS mortars with internal curing by water (W-Z15 and W-Z30) were longer than those of Z0, A-Z15, and A-Z30. This behavior is mainly because, as the slag reaction occurred, water was released as an internal curing liquid by the zeolite sand, thus reducing the alkali ion concentration, slowing down the slag reaction, and leading to an increase in setting time. Secondly, compared to the control group, the setting time of the AAS mortar that was internally cured by the $\mathrm{NaOH}$ solution was slightly reduced. $\mathrm{NaOH}$ as an internal curing solution was released by the zeolite sand, and the slag reaction concentration was maintained at a relatively high level, resulting in an accelerated reaction. Therefore, the setting time was reduced. Finally, A-Z30 had a higher zeolite sand content and more internal curing $\mathrm{NaOH}$ solution was released during the slag reaction. However, on the contrary, the AAS mortar with a high internal curing solution had a longer setting time instead. This is mainly due to the fact that the high zeolite sand content introduced additional pores, resulting in a lower compressive strength and affecting the Vicat needle test results. In general, in this study, two factors influenced the final value of the Vicat needle test, namely the ionic concentration of slag reaction and the number of internal pores [31]. The competing effects of the two factors ultimately determined the setting time. 


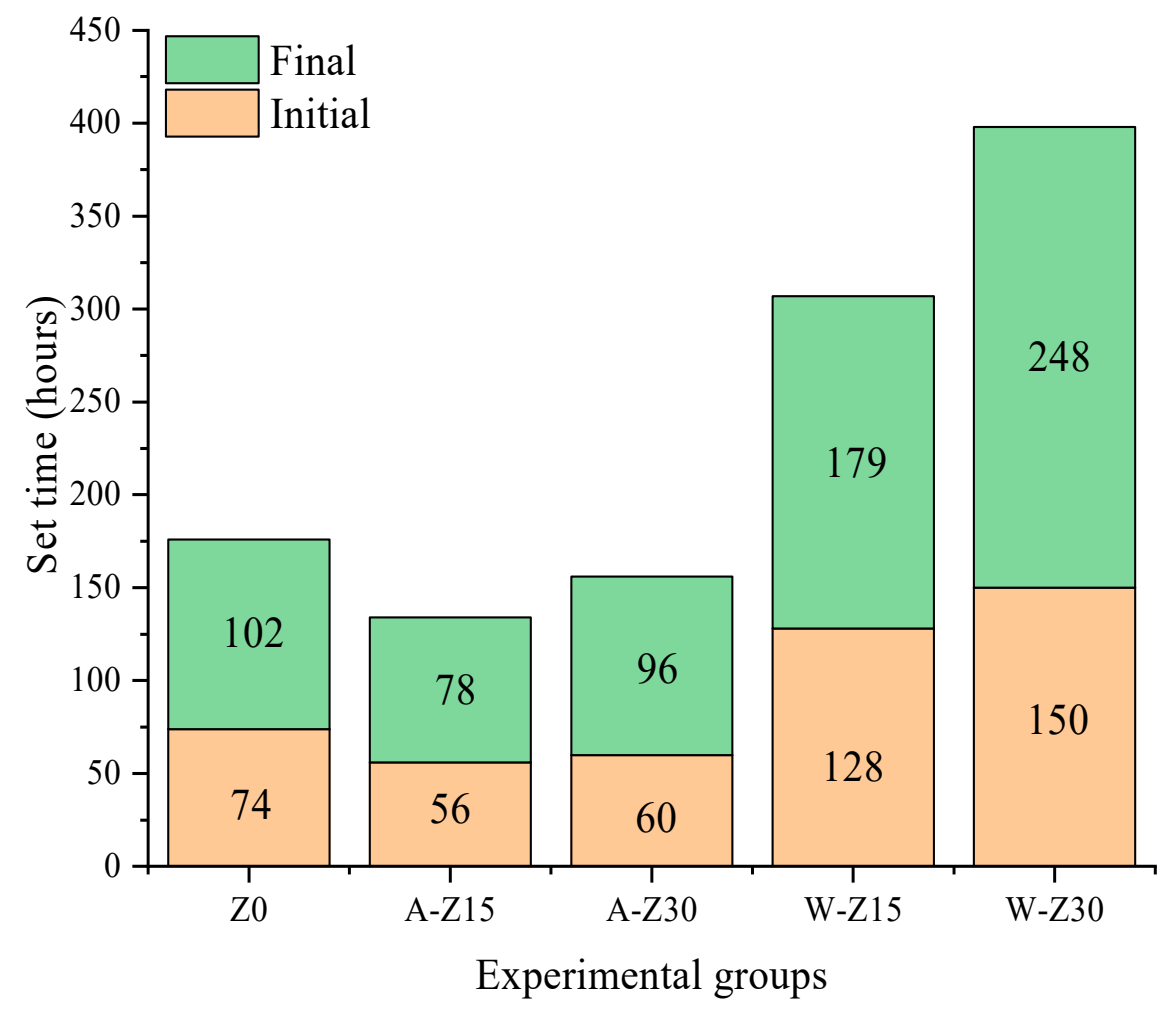

Figure 2. The setting times of all alkali-activated slag (AAS) mortars.

\subsection{Autogenous Shrinkage, Internal Relative Humidity, and Internal Temperature}

Figures 3-7 show the relationship development trends between internal relative humidity (IRH) and autogenous shrinkage (AS) (a) and internal temperature (IT) (b) of all AAS mortars from the final setting time to seven days. The AS variation process can be divided into two stages through the IT variation process of the mortars. The stage of continuous IT change is defined as stage I, and the stage of constant IT change is defined as stage II.
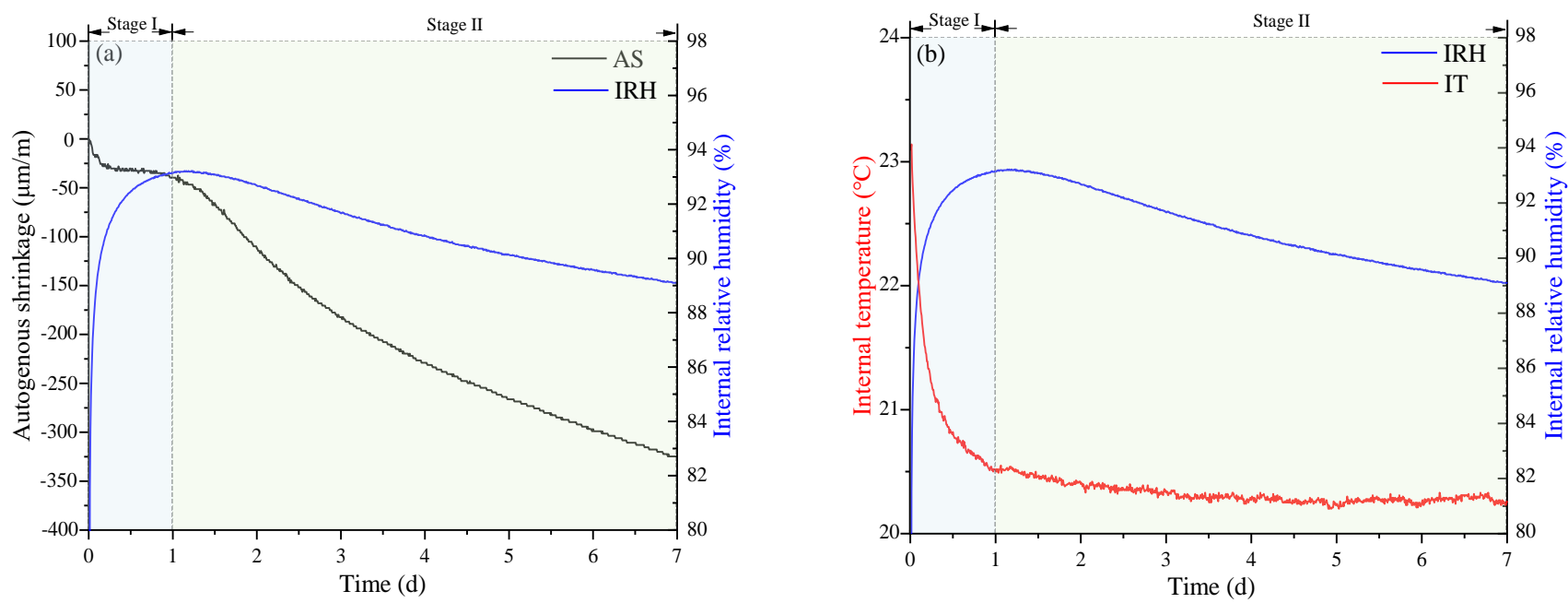

Figure 3. Relationship between IRH and autogenous shrinkage (AS) (a) and IT (b) of Z0. 

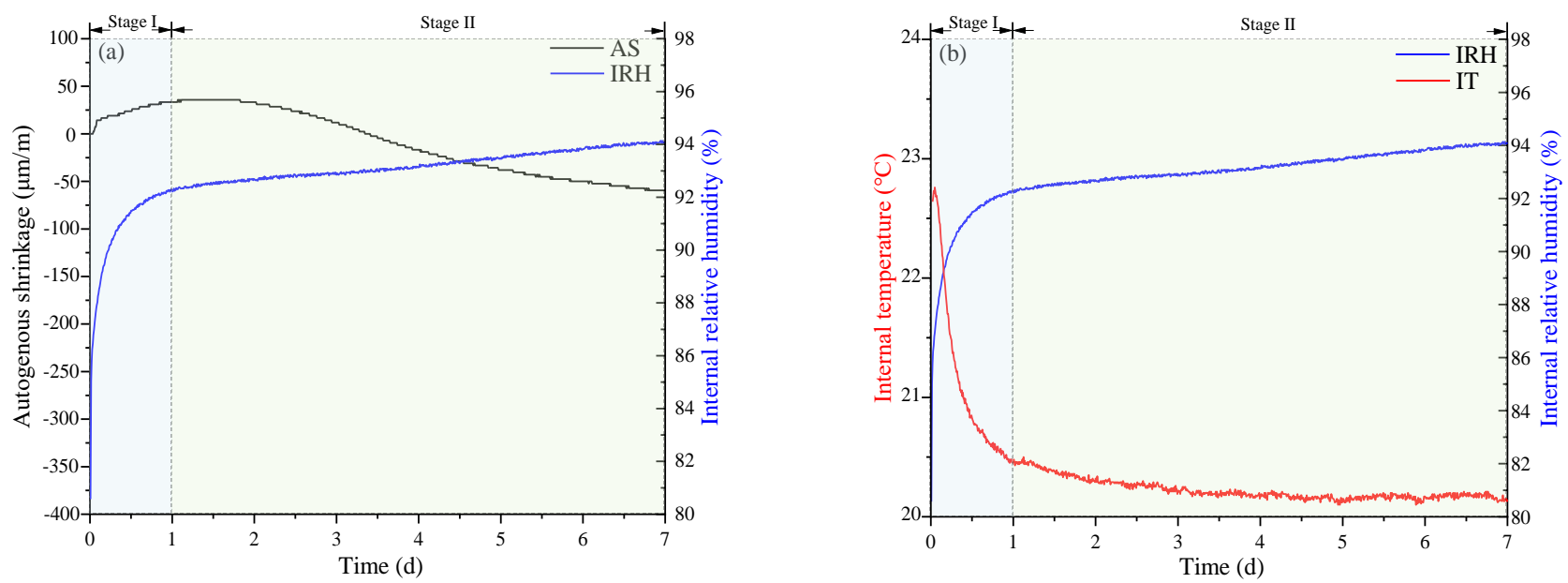

Figure 4. Relationship between IRH and AS (a) and IT (b) of A-Z15.
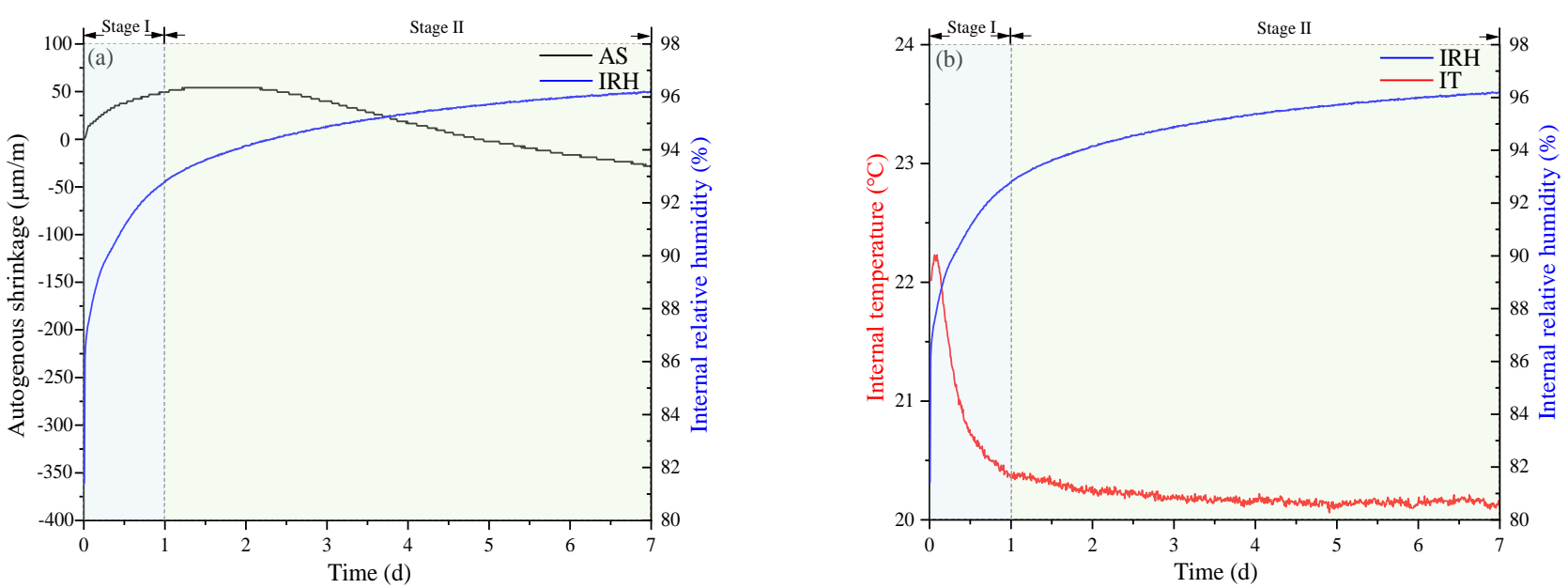

Figure 5. Relationship between IRH and AS (a) and IT (b) of A-Z30.
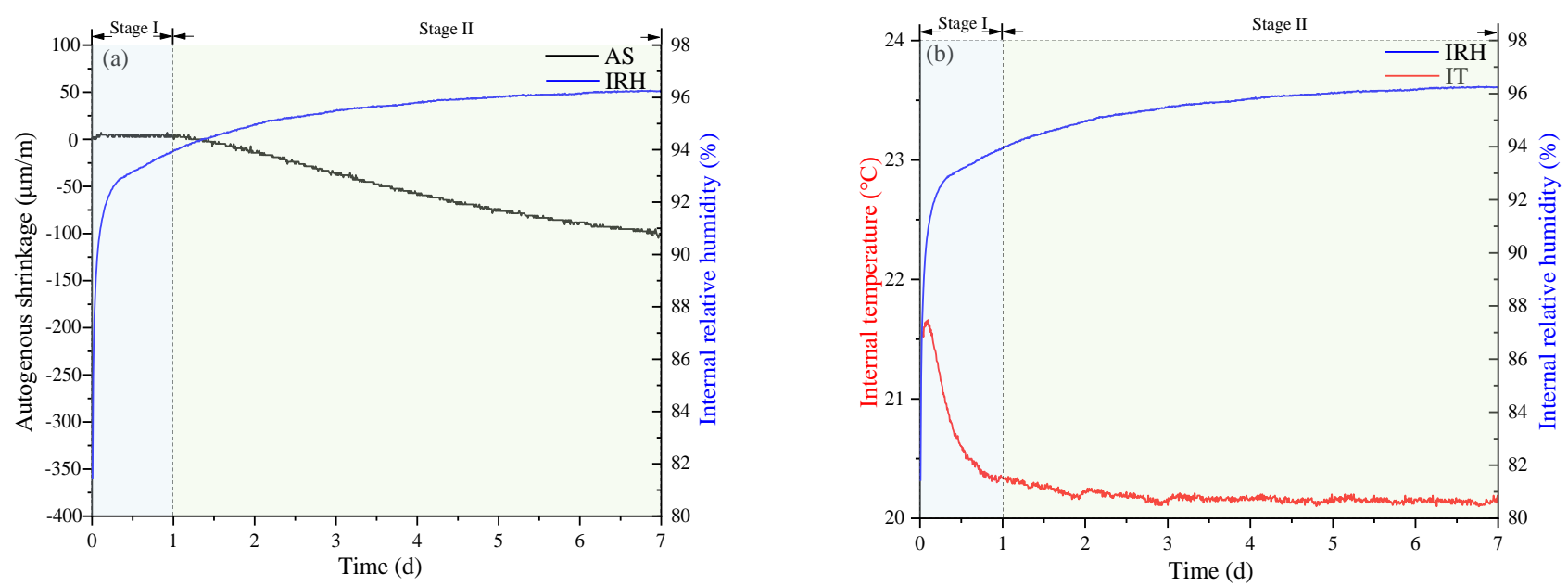

Figure 6. Relationship between IRH and AS (a) and IT (b) of W-Z15. 

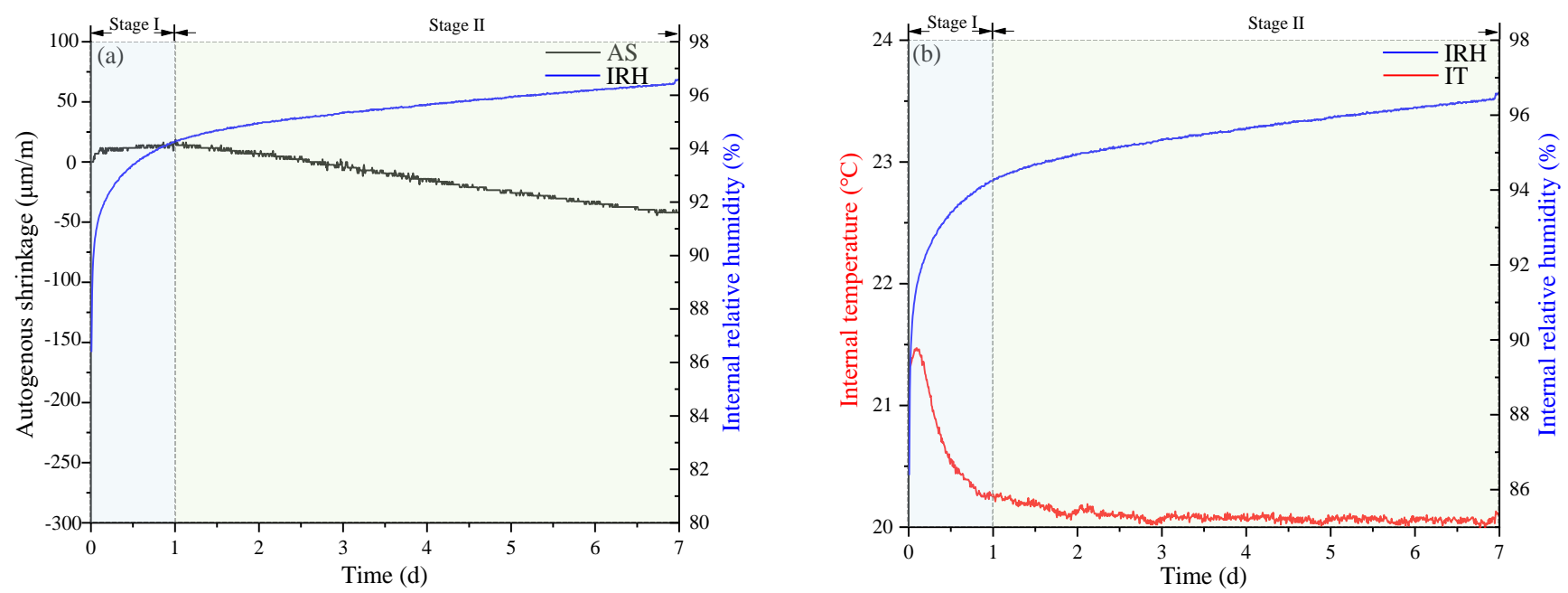

Figure 7. Relationship between IRH and AS (a) and IT (b) of W-Z30.

A previous study [8] reported a continuous decrease in IRH of AAS mortars without internal curing as the slag reaction progresses. However, in the present study, the IRH was continuously elevated at stage I, which was mainly attributed to the release of the liquid inside the ink bottle space after solidification due to IT being above room temperature, and the released liquid resulted in a continuous increase in IRH [32]. In addition, IRH decreases due to the slag reaction. However, the overall IRH elevation trend is shown because the effect of IT influence leading to IRH elevation is significantly greater than the IRH reduction effect due to slag reaction. Fang et al. [33] reported that the alkali-activated slag paste had a continuously elevated IRH during the first day. Similar phenomena were also observed for the other four groups of AAS mortars with internal curing. For the internal curing AAS mortars, the internal curing liquid released by the internal curing agent itself contributed to the most significant increase in IRH, in addition to the two factors mentioned above.

Secondly, in stage II, the IRH of the control group without internal curing (Z0) continued to decrease due to the slag reaction proceeding, and the final IRH value at seven days of age was $89.08 \%$. However, the IRH of all AAS mortars with internal curing was observed to increase continuously. The final IRH values at seven days of age for A-Z15, A-Z30, W-Z15, and W-Z30 were $94.11 \%, 96.21 \%, 96.24 \%$, and $96.61 \%$, respectively. This different trend of IRH variation is mainly due to the internal curing liquid. In this study, zeolite sand as an internal curing agent can continuously release the internal curing liquid, so maintaining the internal of the AAS mortar can maintain a relatively high IRH [34].

Thirdly, for AAS mortars using the same internal curing liquid, higher IRH levels correspond to smaller AS values, which is consistent with what was observed by other researchers [8]. For AAS mortars with water as the internal curing liquid, the final AS values were 102.35 and $42.06 \mu \mathrm{m} / \mathrm{m}$ for W-Z15 and W-Z30, respectively, with AS reductions of $68.48 \%$ and $87.04 \%$, respectively. On the other hand, for AAS mortars with $\mathrm{NaOH}$ solution as the internal curing liquid, the final AS values were 59.51 and $28.24 \mu \mathrm{m} / \mathrm{m}$ for A-Z15 and A-Z30, respectively, with $81.67 \%$ and $91.3 \%$ reductions in AS, respectively. Therefore, $\mathrm{NaOH}$ solution more effectively reduces the AS of AAS mortar than water as an internal curing liquid. The reason for this phenomenon is mainly because the mechanism of reducing AS is different between the two internal curing liquids. The alkali solution as an internal curing liquid is released by the zeolite sand and wets the dry capillaries distributed around the zeolite sand, leading to a reduction in capillary stress and thus a reduction in AS occurrence [35]. On the other hand, water as an internal curing liquid can also wet the pores and thus reduce the pore stress to reduce AS. However, this ability is limited, and as more water is released to reduce the environmental concentration of the slag reaction, there is a dilution effect, thus reducing the slag reaction rate, and the occurrence of AS is inhibited. 
Finally, the factors that reduce the AS of AAS mortars also include the occurrence of expansion. When the expansion is more pronounced, it is more beneficial to reduce the AS at a later age. The occurrence of a clear expansion segment can be clearly observed in Figures 5a and 6a. The expansion maxima values of A-Z15 and A-Z30 were 35.71 and $54.13 \mu \mathrm{m} / \mathrm{m}$, respectively, and the expansion effects lasted for 3.34 and 4.82 days, respectively. On the other hand, a very weak expansion effect was observed for AAS mortars with water as the internal curing liquid. The expansion maxima values of 4.76 and $18.69 \mu \mathrm{m} / \mathrm{m}$ were observed for $\mathrm{W}-\mathrm{Z} 15$ and $\mathrm{W}-\mathrm{Z} 30$ and lasted for 1.21 and 2.57 days, respectively. Some researchers have reported that the main cause of expansion is the formation of silica-rich gels [21]. The alkali solution released by zeolite sand provides sufficient internal curing liquid, and thus suitable conditions for the formation of expansion [35].

\subsection{Isothermal Calorimetry}

Figure 8 shows the heat flow (a) and cumulative heat (b) curves of Z0, A-Z15, A-Z30, $\mathrm{W}-\mathrm{Z15}$, and W-Z30 for casting over three days. Two heat flow peaks have been reported in the past when sodium hydroxide solution was used as an activator in AAS mortars [21]. This was also found in the present study, as shown in Figure 8a. The first peak is shown independently. Firstly, from the first peak, it was observed that the heat flow peak intensity of the AAS mortar with $\mathrm{NaOH}$ solution as the internal curing liquid was higher compared to Z0. This behavior occurs mainly because the high $\mathrm{Na} 2 \mathrm{O}$ content increases the first peak intensity [36]. On the other hand, for the AAS mortar with water as the internal curing liquid, the first peak intensity of the heat flow peak was lower than that of $\mathrm{Z} 0$ due to the water released from the zeolite sand diluting the concentration of alkali ions for the slag reaction, resulting in a lower slag reaction rate. Secondly, observation of the second peak revealed that the peak of the AAS mortar containing internal curing was advanced by about $6.5-8.9 \mathrm{~h}$ compared to that of Z0. This behavior is due to the increased Ca2+ adsorbed by the fine particle size zeolite particles from the zeolite sand used in this study, which promotes the slag hydration reaction [37].

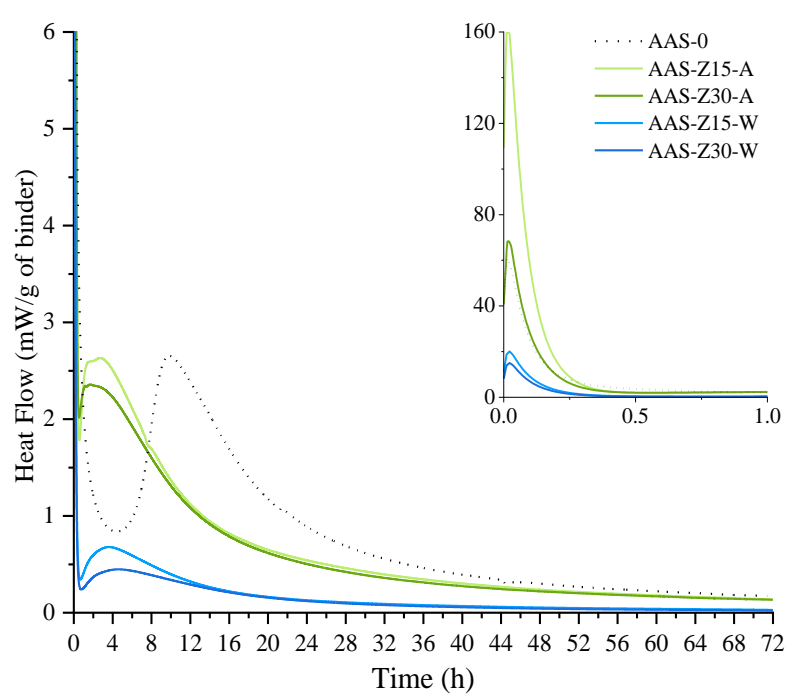

(a)

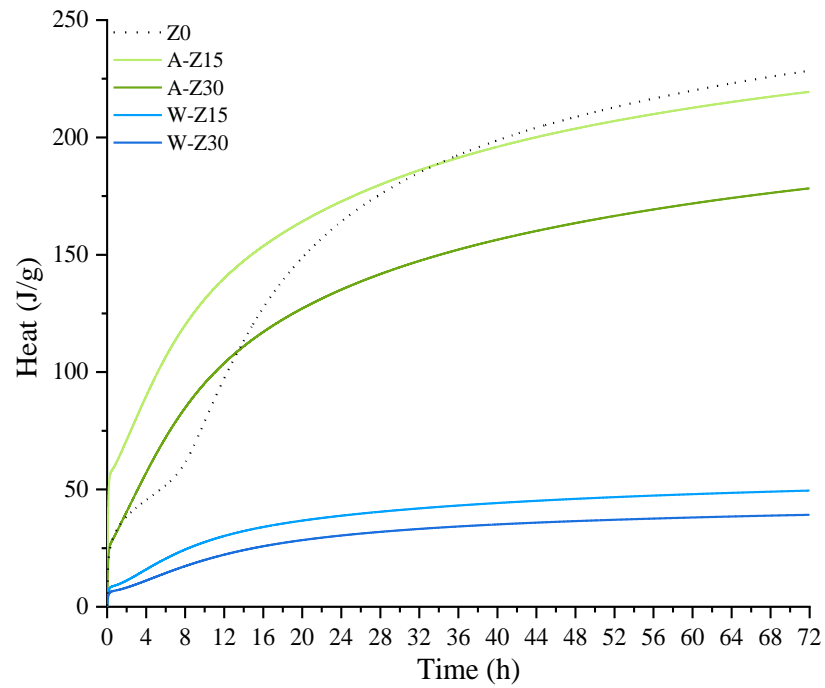

(b)

Figure 8. Isothermal calorimetry results for $72 \mathrm{~h}$ : (a) heat flow; (b) cumulative heat.

Figure $8 \mathrm{~b}$ shows the cumulative heat of AAS mortars. At three days of age, the final heats of Z0, A-Z15, A-Z30, W-Z15, and W-Z30 were 228.3, 219.4, 71.9, 162.2, and $39.2 \mathrm{~J} / \mathrm{g}$, respectively. Firstly, it can be clearly observed that the cumulative heat of the AAS mortar using water for internal curing is substantially reduced compared to the control group. This is mainly due to the dilution of the ionic concentration of the slag reaction by releasing 
water from the zeolite sand, resulting in a weaker slag reaction. Secondly, observation of the accumulated heat of AAS mortar with $\mathrm{NaOH}$ solution as the internal curing liquid revealed that the total heat release of the mortar decreased as the amount of internal curing liquid increased. A similar phenomenon was reported in the study by Gebregziabiher [8]. Gebregziabiher et al. [8] found that high concentrations of $\mathrm{NaOH}$ reduced the heat release of AAS pastes.

\subsection{Compressive Strength}

Figure 9 shows the compressive strength results of Z0, A-Z15, A-Z30, W-Z15, and WZ30. Firstly, for the AAS mortars with $\mathrm{NaOH}$ solution as internal curing liquid, compared with Z0, the compressive strength increased as the zeolite sand amount increased. The main reason for this phenomenon is that more sodium hydroxide solution being released from the zeolite sand increased the ionic concentration of the slag reaction, leading to an increase in hydration productions; therefore, the compressive strength was increased. On the other hand, compared with the control group, for the AAS mortar with water as the internal curing liquid, the compressive strength of W-Z15 was slightly higher at three days, but the compressive strength was slightly lower at seven days. When the zeolite sand amount was increased to $30 \mathrm{wt} \%$, the compressive strengths at three and seven days decreased by $20.1 \%$ and $13.8 \%$, respectively. The decrease in compressive strength occurred when water was used as an internal curing liquid in the AAS mortar. This is mainly attributed to the fact that water is released during the slag reaction to reduce the ionic concentration. Thus, the slag reaction is slowed down and the strength is reduced. In addition, research has reported that the zeolite lightweight aggregate used as an internal curing agent in concrete does not cause a loss of compressive strength [38], so it is clear that the main reason for the reduction in compressive strength of AAS mortar in this study is the dilution effect of the internal curing liquid, water.

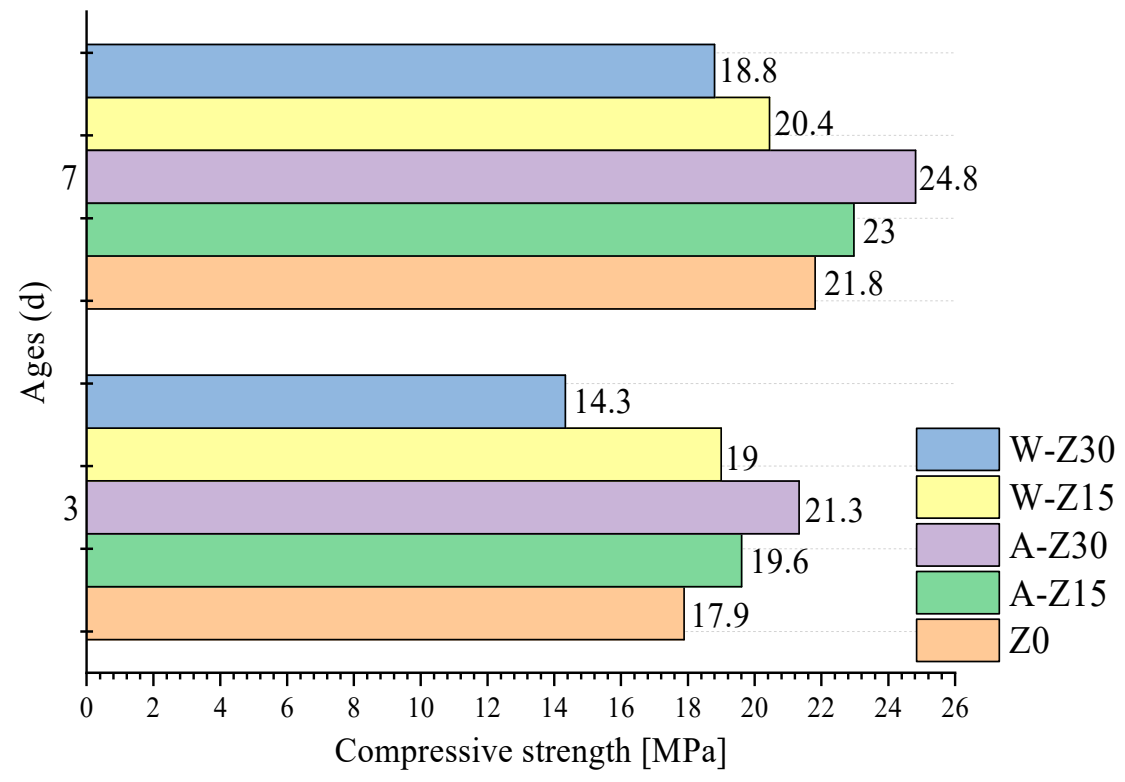

Figure 9. Compressive strength of AAS mortars at days 3 and 7.

\subsection{Ultrasonic Pulse Velocity (UPV) Test}

Figure 10 shows the UPV results of Z0, A-Z15, A-Z30, W-Z15, and W-Z30 specimens at three and seven days of age. Wang et al. [39] purported a positive correlation between UPVs and compressive strength values. Nevertheless, the experimental phenomenon observed in the present study is different. Firstly, the UPV decreases as the content of zeolite sand that replaces the standard sand increases. This occurs mainly because the addition of zeolite sand into the mortar matrix leads to more additional pores being added, 
thus increasing the pore amount of the AAS mortar and resulting in a decrease in the UPVs. Therefore, it can be clearly concluded that the addition of zeolite sand decreases the UPVs. Secondly, the UPVs of the AAS mortar increase with age. This behavior is mainly due to the fact that the slag reacts with increased curing age to produce more hydration productions, making the mortar denser and reducing the UPVs. Finally, the seven-day UPVs of AAS0, A-Z15, A-Z30, W-Z15, and W-Z30 were 4016, 3745, 3571.5, 3692, and $3597 \mathrm{~m} / \mathrm{s}$, respectively. In summary, the factors influencing the UPVs in this study come down to two points: the amount of zeolite sand added and the number of hydration productions generated. The introduction of zeolite sand introduces additional pores that reduce the UPVs and, conversely, the reaction productions increase the UPVs. The effect of the introduction of zeolite sand in this study is significantly greater than the reaction products.

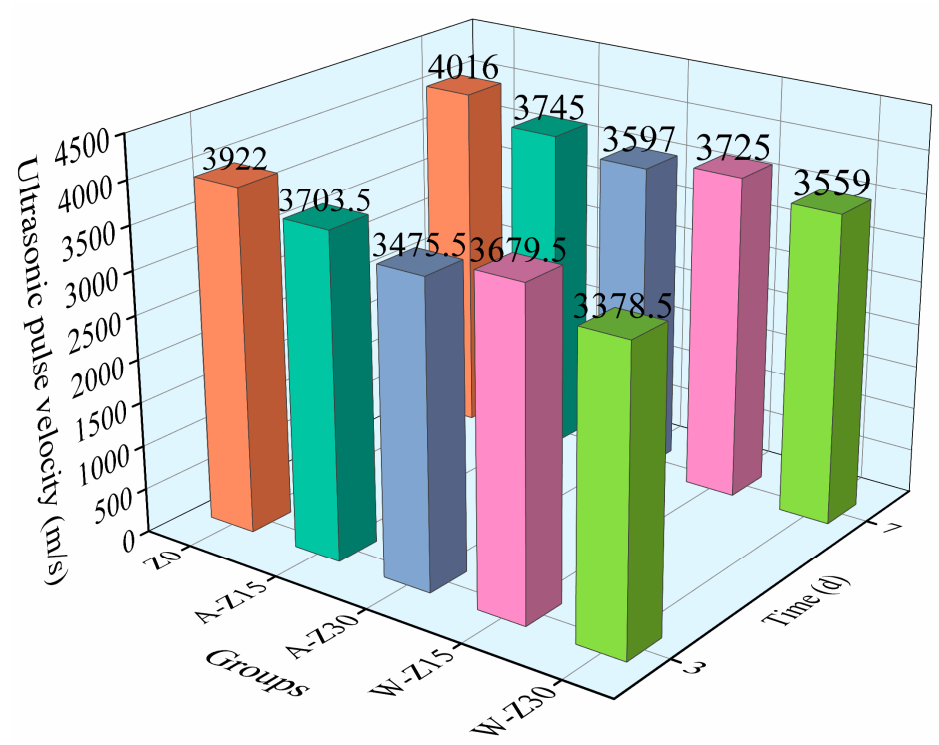

Figure 10. Ultrasonic pulse velocity values of Z0, A-Z15, A-Z30, W-Z15, and W-Z30 specimens at days 3 and 7 .

\subsection{Surface Electrical Resistivity (SER)}

SER assessed the resistance of AAS mortars to chloride ions by measuring the resistivity of AAS mortars. The resistivity of AAS mortars is dependent on the pore size distribution, interpore connectivity, and saturation, etc., as reported in [40]. The SER is also considered by researchers as one of the tests to indirectly measure porosity and diffusion capacity. Various icons, such as $\mathrm{K}^{+}, \mathrm{Ca}^{2+}, \mathrm{OH}^{-}$, etc., are found in AAS mortars. When these ions flow, an electric current is generated. The OH- concentration in the pores of AAS mortars depends on the alkali concentration [41].

Figure 11 shows the SER results for AAS mortars at three and seven days of age. Firstly, the SER values of AAS mortars increased as the age increased. This is due to the fact that as the age of the curing age increases, the slag reaction continues to consume a large number of ions, resulting in a lower content of mobile ions and, therefore, having a lower ionic conductivity and a higher SER value. Secondly, when internal curing is carried out with water as the internal curing liquid, the SER values of the AAS mortar are higher than when the alkali solution is used as the internal curing liquid. This behavior is mainly due to the fact that, as the slag reaction proceeds, water is released by the zeolite sand, reducing the ambient alkali concentration around the slag reaction, which in turn reduces the ionic conductivity and leads to an increase in SER. Finally, when the replacement rate of the standard sand increased from $15 \%$ to $30 \%$, the SER values decreased significantly. This is mainly due to the use of more internal curing agent introducing additional pores, resulting in the formation of a relatively sparse pore network where the flow of ions 
becomes smoother and thus the ionic conductivity increases, which ultimately manifests itself as a decrease in SER values.

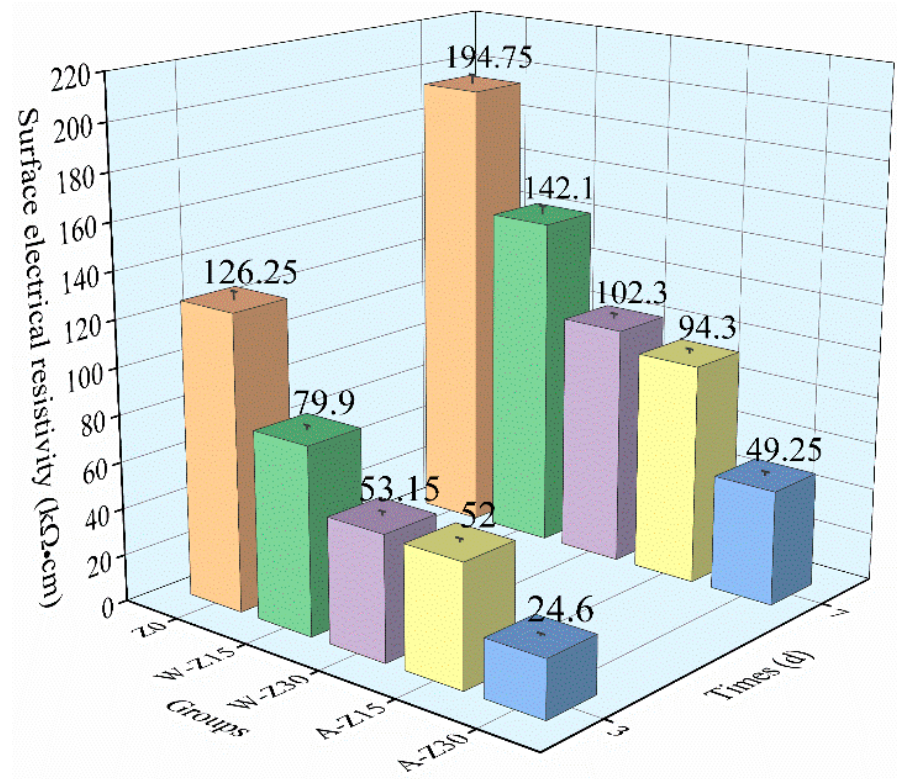

Figure 11. Surface Electrical Resistivity (SER) of Z0, A-Z15, A-Z30, W-Z15, and W-Z30 specimens at days 3 and 7 .

\section{Conclusions}

This study shows the effect of types of internal curing liquids $(\mathrm{NaOH}$ solution and deionized water) on the properties of alkali-activated slag (AAS) mortar. Z0 was the control specimen, and W-Z15 and W-Z30 had water as the internal curing liquid and zeolite sand replacing 15\% and 30\% of standard sand, respectively. A-Z15 and A-Z30 had $\mathrm{NaOH}$ as the internal curing liquid, with zeolite sand replacing $15 \%$ and $30 \%$ of standard sand, respectively. Various experiments were performed, culminating in the following conclusions:

1. The setting times of AAS mortars with internal curing by water (W-Z15 and W-Z30) were longer than those of Z0, A-Z15, and A-Z30. This behavior is mainly because, as the slag reaction occurs, water is released as an internal curing liquid by the zeolite sand, thus reducing the alkali ion concentration and slowing down the slag reaction, leading to an increase in setting time.

2. For AAS mortars with water as the internal curing liquid, the final AS values were 102.35 and $42.06 \mu \mathrm{m} / \mathrm{m}$ for W-Z15 and W-Z30, respectively. On the other hand, for the AAS mortars with $\mathrm{NaOH}$ solution as the internal curing liquid, the final AS values were 59.51 and $28.24 \mu \mathrm{m} / \mathrm{m}$ for A-Z15 and A-Z30, respectively. Therefore, the $\mathrm{NaOH}$ solution reduces the AS of AAS mortar more effectively than water as an internal curing liquid.

3. The maximum expansion values of A-Z15 and A-Z30 were 35.71 and $54.13 \mu \mathrm{m} / \mathrm{m}$, respectively, and the expansion effect lasted for 3.34 and 4.82 days, respectively. On the other hand, a very weak expansion effect was observed for AAS mortars with water as the internal curing liquid. The expansion maxima values for 4.76 and $18.69 \mu \mathrm{m} / \mathrm{m}$ were observed for W-Z15 and W-Z30, which lasted for 1.21 and 2.57 days, respectively.

4. At three days of age, the final heats of Z0, A-Z15, A-Z30, W-Z15, and W-Z30 were $228.3,219.4,71.9,162.2$, and $39.2 \mathrm{~J} / \mathrm{g}$, respectively. The cumulative heat of the AAS mortar, using water for internal curing, was substantially reduced compared to the control group. This was mainly due to the dilution of the ionic concentration by water released from the zeolite sand, resulting in a weaker slag reaction. 
5. For the AAS mortars with $\mathrm{NaOH}$ solution as the internal curing liquid, compared with $\mathrm{Z} 0$, the compressive strength increased as the amount of zeolite sand increased. In addition, at the age of seven days, a decrease in compressive strength values occurred when water was used as the internal curing liquid in the AAS mortar. This is mainly attributed to the fact that water is released to reduce the ionic concentration.

6. The seven-day UPVs of AAS0, A-Z15, A-Z30, W-Z15, and W-Z30 were 4016, 3745, $3571.5,3692$, and $3597 \mathrm{~m} / \mathrm{s}$, respectively. The UPV decreased as the content of zeolite sand that replaced the standard sand increased. The introduction of zeolite sand introduced additional pores that reduced the UPVs; conversely, the reaction products increased the UPVs. The experimental results depended on the competition between various factors.

7. When internal curing was carried out with water as the internal curing liquid, the surface resistivity values of the AAS mortar were higher than when the alkali solution was used as the internal curing liquid. This is because as the slag reaction proceeded, water was released by the zeolite sand, reducing the ambient alkali concentration and the ionic conductivity.

Author Contributions: Conceptualization, X.-Y.W.; Formal analysis, G.-Z.Z. and Y.H.; Funding acquisition, X.-Y.W.; Investigation, G.-Z.Z. and J.-Y.L.; Methodology, X.-Y.W.; Writing-original draft, G.-Z.Z. and X.-Y.W.; Writing-review and editing, G.-Z.Z., T.-W.K., and X.-Y.W. All authors have read and agreed to the published version of the manuscript.

Funding: This research was supported by the Basic Science Research Program through the National Research Foundation of Korea (NRF), funded by the Ministry of Science, ICT and Future Planning (no. 2015R1A5A1037548), and an NRF grant (no. NRF-2020R1A2C4002093).

Institutional Review Board Statement: Not applicable.

Informed Consent Statement: Not applicable.

Data Availability Statement: The data presented in this study are available from the corresponding author upon a reasonable request.

Conflicts of Interest: The authors declared that they have no conflict of interest in this work. We declare that we do not have any commercial or associative interest that represents a conflict of interest in connection with the work submitted.

\section{References}

1. McLellan, B.C.; Williams, R.P.; Lay, J.; van Riessen, A.; Corder, G.D. Costs and carbon emissions for geopolymer pastes in comparison to ordinary portland cement. J. Clean. Prod. 2011, 19, 1080-1090. [CrossRef]

2. Yang, K.-H.; Song, J.-K.; Song, K.-I. Assessment of $\mathrm{CO}_{2}$ reduction of alkali-activated concrete. J. Clean. Prod. 2013, 39, 265-272. [CrossRef]

3. Duxson, P.; Fernández-Jiménez, A.; Provis, J.L.; Lukey, G.C.; Palomo, A.; van Deventer, J.S.J. Geopolymer technology: The current state of the art. J. Mater. Sci. 2006, 42, 2917-2933. [CrossRef]

4. Wang, S.-D.; Pu, X.-C.; Scrivener, K.L.; Pratt, P.L. Alkali-activated slag cement and concrete: A review of properties and problems. Adv. Cem. Res. 1995, 27, 93-102. [CrossRef]

5. Melo Neto, A.A.; Cincotto, M.A.; Repette, W. Drying and autogenous shrinkage of pastes and mortars with activated slag cement. Cem. Concr. Res. 2008, 38, 565-574. [CrossRef]

6. Li, Z.; Nedeljković, M.; Chen, B.; Ye, G. Mitigating the autogenous shrinkage of alkali-activated slag by metakaolin. Cem. Concr. Res. 2019, 122, 30-41. [CrossRef]

7. Yang, L.Y.; Jia, Z.J.; Zhang, Y.M.; Dai, J.G. Effects of nano-TiO2 on strength, shrinkage and microstructure of alkali activated slag pastes. Cem. Concr. Compos. 2015, 57, 1-7. [CrossRef]

8. Song, C.; Choi, Y.C.; Choi, S. Effect of internal curing by superabsorbent polymers-Internal relative humidity and autogenous shrinkage of alkali-activated slag mortars. Constr. Build. Mater. 2016, 123, 198-206. [CrossRef]

9. Bilim, C.; Karahan, O.; Atiş, C.D.; Illkentapar, S. Influence of admixtures on the properties of alkali-activated slag mortars subjected to different curing conditions. Mater. Des. 2013, 44, 540-547. [CrossRef]

10. Wyrzykowski, M.; Ghourchian, S.; Sinthupinyo, S.; Chitvoranund, N.; Chintana, T.; Lura, P. Internal curing of high performance mortars with bottom ash. Cem. Concr. Compos. 2016, 71, 1-9. [CrossRef]

11. Kevern, J.T.; Nowasell, Q.C. Internal curing of pervious concrete using lightweight aggregates. Constr. Build. Mater. 2018, 161, 229-235. [CrossRef] 
12. Holt, E. Early Age Autogenous Shrinkage of Concrete: Dissertation; University of Washington: Espoo, Finland, 2001.

13. Bentz, D.P.; Snyder, K.A. Protected paste volume in concrete: Extension to internal curing using saturated lightweight fine aggregate. Cem. Concr. Res. 1999, 29, 1863-1867. [CrossRef]

14. Mo, L.; Fang, J.; Huang, B.; Wang, A.; Deng, M. Combined effects of biochar and MgO expansive additive on the autogenous shrinkage, internal relative humidity and compressive strength of cement pastes. Constr. Build. Mater. 2019, $229,116877$. [CrossRef]

15. Liu, F.; Wang, J.; Qian, X.; Hollingsworth, J. Internal curing of high performance concrete using cenospheres. Cem. Concr. Res. 2017, 95, 39-46. [CrossRef]

16. Liu, K.; Yu, R.; Shui, Z.; Yi, S.; Li, X.; Ling, G.; He, Y. Influence of external water introduced by coral sand on autogenous shrinkage and microstructure development of Ultra-High Strength Concrete (UHSC). Constr. Build. Mater. 2020, 252, 119111. [CrossRef]

17. Li, Z.; Wyrzykowski, M.; Dong, H.; Granja, J.; Azenha, M.; Lura, P.; Ye, G. Internal curing by superabsorbent polymers in alkali-activated slag. Cem. Concr. Res. 2020, 135, 106123. [CrossRef]

18. Oh, S.; Choi, Y.C. Superabsorbent polymers as internal curing agents in alkali activated slag mortars. Constr. Build. Mater. 2018, 159, 1-8. [CrossRef]

19. Liu, J.; Farzadnia, N.; Shi, C. Effects of superabsorbent polymer on interfacial transition zone and mechanical properties of ultra-high performance concrete. Constr. Build. Mater. 2020, 231, 117142. [CrossRef]

20. Luukkonen, T.; Abdollahnejad, Z.; Yliniemi, J.; Kinnunen, P.; Illikainen, M. One-part alkali-activated materials: A review. Cem. Concr. Res. 2018, 103, 21-34. [CrossRef]

21. Sakulich, A.R.; Bentz, D.P. Mitigation of autogenous shrinkage in alkali activated slag mortars by internal curing. Mater. Struct. 2012, 46, 1355-1367. [CrossRef]

22. Ballekere Kumarappa, D.; Peethamparan, S.; Ngami, M. Autogenous shrinkage of alkali activated slag mortars: Basic mechanisms and mitigation methods. Cem. Concr. Res. 2018, 109, 1-9. [CrossRef]

23. Lee, N.K.; Abate, S.Y.; Kim, H.-K. Use of recycled aggregates as internal curing agent for alkali-activated slag system. Constr. Build. Mater. 2018, 159, 286-296. [CrossRef]

24. Farzanian, K.; TeixeiraI, K.P.; Rocha, P.; Carneiro, L.D.S.; Ghahremaninezhad, A. The mechanical strength, degree of hydration, and electrical resistivity of cement pastes modified with superabsorbent polymers. Constr. Build. Mater. 2016, 109, 156-165. [CrossRef]

25. ASTM International. Standard Test Methods for Time of Setting of Hydraulic Cement by Vicat Needle; ASTM International: West Conshohocken, PA, USA, 2019.

26. C1698, A. Standard Test Method for Autogenous Strain of Cement Paste and Mortar; ASTM International: West Conshohocken, PA, USA, 2016.

27. Zhang, G.-Z.; Lee, H.-S.; Wang, X.-Y. Autogenous Shrinkage, Strength, and Hydration Heat of Ultra-High-Strength Paste Incorporating Nano-Zirconium Dioxide. Sustainability 2020, 12, 9372. [CrossRef]

28. Zhang, G.-Z.; Cho, H.-K.; Wang, X.-Y. Effect of Nano-Silica on the Autogenous Shrinkage, Strength, and Hydration Heat of Ultra-High Strength Concrete. Appl. Sci. 2020, 10, 5202. [CrossRef]

29. ASTM International. Standard Test Method for Compressive Strength of Cylindrical Concrete Specimens; ASTM International: West Conshohocken, PA, USA, 2016.

30. ASTM International. Standard Test Method for Pulse Velocity through Concrete; ASTM International: West Conshohocken, PA, USA, 2016.

31. Ren, M.; Wen, X.; Gao, X.; Liu, Y. Thermal and mechanical properties of ultra-high performance concrete incorporated with microencapsulated phase change material. Constr. Build. Mater. 2020, 273, 121714. [CrossRef]

32. Ishida, T.; Maekawa, K.; Kishi, T. Enhanced modeling of moisture equilibrium and transport in cementitiousmaterials under arbitrary temperature and relative humidity history. Cem. Concr. Res. 2006, 37, 565-578. [CrossRef]

33. Fang, G.; Bahrami, H.; Zhang, M. Mechanisms of autogenous shrinkage of alkali-activated fly ash-slag pastes cured at ambient temperature within $24 \mathrm{~h}$. Constr. Build. Mater. 2018, 171, 377-387. [CrossRef]

34. Zhang, G.Z.; Wang, X.Y. Effect of Pre-Wetted Zeolite Sands on the Autogenous Shrinkage and Strength of Ultra-High-Performance Concrete. Materials 2020, 13, 2356. [CrossRef] [PubMed]

35. Chen, P.; Wang, J.; Wang, L.; Xu, Y. Perforated cenospheres: A reactive internal curing agent for alkali activated slag mortars. Cem. Concr. Compos. 2019, 104, 103351. [CrossRef]

36. Gebregziabiher, B.S.; Thomas, R.; Peethamparan, S. Very early-age reaction kinetics and microstructural development in alkaliactivated slag. Cem. Concr. Compos. 2015, 55, 91-102. [CrossRef]

37. Burris, L.E.; Juenger, M.C.G. Milling as a pretreatment method for increasing the reactivity of natural zeolites for use as supplementary cementitious materials. Cem. Concr. Compos. 2016, 65, 163-170. [CrossRef]

38. Zhang, J.; Ding, X.; Wang, Q.; Zheng, X. Effective solution for low shrinkage and low permeability of normal strength concrete using calcined zeolite particles. Constr. Build. Mater. 2018, 160, 57-65. [CrossRef]

39. Wang, C.-C.; Wang, H.-Y. Assessment of the compressive strength of recycled waste LCD glass concrete using the ultrasonic pulse velocity. Constr. Build. Mater. 2017, 137, 345-353. [CrossRef] 
40. Dávila-Pompermayer, R.; Lopez-Yepez, L.G.; Valdez-Tamez, P.; Juárez, C.A.; Durán-Herrera, A. Lechugilla natural fiber as internal curing agent in self compacting concrete (SCC): Mechanical properties, shrinkage and durability. Cem. Concr. Compos. 2020, 112, 103686. [CrossRef]

41. Vollpracht, A.; Lothenbach, B.; Snellings, R.; Haufe, J. The pore solution of blended cements: A review. Mater. Struct. 2015, 49, 3341-3367. [CrossRef] 